\title{
Estudio de los aportes hídricos al parque natural de la Albufera de Valencia
}

\author{
J. M. Soria y E. Vicente. \\ Dep. Microbiología y Ecología. Facultad Ciencias Biológicas. Universidad de Valencia. \\ 46100 - Burjassot (Valencia), Spain
}

\section{RESUMEN}

El Parque Natural de la Albufera de Valencia (superficie $211 \mathrm{~km}^{2}$ ) recibe aportes hidricos de diversa procedencia: escorrentias naturales. aportaciones subterráneas. aguas residuales y aguas sobrantes de riego. El volumen total anual de las aportaciones al Parque es de $484 \mathrm{hm}^{3}$ año' llegando hasta el propio lago de la Albufera (23 $\mathrm{km}^{2}$ de superficie) un promedio de 280 hm $^{3}$ año'. Sin embargo, el Plan Hidrológico de la Cuenca del Jícar establece unas aportaciones mínimas de $100 \mathrm{hm}^{3}$ año-1 para el Parc Natural, volumen que, si no se complementa con otros aportes (principalmente sobrantes de riego), estimamos insuficiente para mantener la calidad ecológica del ecosistema.

Palabras clave: Albufera de Valencia. aportes hidricos. escorrentias. balance hidrico. lagunas costeras

\begin{abstract}
The Natural Park of the Albufera de Valencia (surface area $211 \mathrm{~km}^{2}$ ) receives water from various sources, i.e. natural runoff, groundwater discliarge, sewage and from irrigation surplus waters. The total annual volume ofwater discharged to the Natural Park is $484 \mathrm{hm}^{3} \mathrm{yr}^{-1}$. An average $280 \mathrm{hm}^{\prime} \mathrm{yr}^{-1}$ reachec the lake itself (surface area $23 \mathrm{~km}^{2}$ ). However, the Hydrological Management Plan for the bacin of River Júcar, including the Natural Park, only establishes a minimum water discharge to the Park of $100 \mathrm{hm}^{3} \mathrm{yr}^{-1}$. We conclude that the ecological quality of the ecosystem will deterioratc if no additional input of water to the Park is provided (e.g. irrigation surpluses).
\end{abstract}

Keywords: Albufera of Valencia, water discharge, runoff, water budget, coastal lagoon.

\section{INTRODUCCIÓN}

El sistema formado por la Albufera de Valencia, el humedal circundante y la restinga adyacente a ambos adquirió el régimen jurídico de Parque Natural por decreto de la Generalitat Valenciana de 8 de julio de 1986. La importancia ecológica que presenta este espacio natural quedó puesta de manifiesto con su incorporación el 8 de mayo de 1990 a la lista de humedales de importancia internacional designada por el Gobierno español, establecida en virtud del Convenio relativo a humedales de importancia internacional, especialmen- te como hábitat de aves acuáticas, hecho en Rainsar (Irán) el 2 de febrero de 1971. El marjal primitivo está ocupado en su gran mayoría por arrozales, quedando apenas algunas hectáreas en su estado más natural, que serían principalmente las masas de vegetación perimetral de la Albufera y las varias islas o mates contenidas en el propio lago, el tancat de Sacarés y el ullal de Baldoví. Numerosos trabajos se han publicado en los últimos años sobre las características eutróficas de la Albufera y su plancton, y otros muchos se siguen realizando con el fin de conocer la estructura funcional del ecosistema. 
Sin embargo, un dato fundamental para el conocimiento del ecosistema es saber cuáles son los aportes de agua al Parque, sus orígenes y su distribución a lo largo y ancho de sus 21120 hectáreas de extensión (Sánchez, 1991). El libro más reciente de Rosselló (1995) sobre la Albufera de Valencia es la recopilación de la información existente hasta los años 90, y tampoco clarifica este punto. Pese a todo, el Plan Hidrológico de la Cuenca del Júcar establece unas aportaciones mínimas de 100 hm $^{3}$ año-' (B.O.E. 27-8-99) para el Parc Natural, volumen que, según veremos, estimamos insuficiente para mantener la calidad del ecosistema.

La Albufera de Valencia es una laguna litoral situada en la zona centro-norte del Pare Natural. Su forma es casi circular, de unos $8 \mathrm{~km}$ de diámetro máximo. Mediciones de la superficie de la Albufera por medio de imágenes del satélite Landsat-V estiman la superficie, incluyendo los fitoestromas de vegetación interna (mates), como la Mata del Fang, Sant Roc, La Manseguerota y L'Antina, en 2320 hectáreas (Caselles, López y Soria, 1986). Su profundidad media es de aproximadamente $1.2 \mathrm{~m}$. Ocupa la parte central del humedal que se extiende entre las desembocaduras de los ríos Turia y Júcar, en su mayor parte dedicado al cultivo del arroz. La comunicación de la Albufera con el mar se lleva a cabo por tres canales o "golas" donde el flujo de agua es regulado por compuertas que mantienen su nivel en los valores más adecuados para el ciclo de cultivo del arrozal. Al Norte y Oeste de la zona húmeda se sitúa un cordón de poblaciones que suman 428123 habitantes (censo de 1989) y varios miles de pequeñas, medianas y grandes industrias, cuyas aguas residuales se vierten, en parte sin depurar, a cauces naturales pertenecientes a la cuenca hidrográfica de la Albufera. Tenemos constancia que al menos eran 206 las industrias que lo hacían directamente a cauces públicos (datos de 1988), mientras que las demás (varios centenares, sin que pueda precisarse la cifra) lo hacían al alcantarillado municipal, que en los años del estudio (entre 1985 y 1988) vertía luego a acequias que terminaban en la Albufera.

Los aportes hídricos llegan por numerosas acequias con aguas procedentes de los ríos Turia y
Júcar y de varios barrancos. Si bien la parte Norte de la zona húmeda era anteriormente abastecida por el caudal del Turia, derivado por las acequias de riego de la Vega de Valencia de la margen derecha de este río y la acequia del Oro, en la actualidad y debido al trasvase de aguas del río Júcar al Turia, y la canalización de las aguas de salida de la depuradora de aguas residuales de la Ciudad de Valencia (EDAR de Pinedo) y de los colectores de diversas poblaciones de la cuenca (Quart, Xirivella, Aldaia, Alaquas, entre otras), los aportes en esta zona corresponden a aguas de muy diversa composición y procedencia. Las zonas Oeste y Sur, por otra parte, se surten de las aguas del Júcar, de algunos vertidos de poblaciones (Almussafes, Benifaió, Alginet, Sollana, Sueca, entre otras) y de las numerosas surgencias de la zona, más conocidas como ullals.

Estas características condicionan la evolución anual de los diferentes parámetros, diferenciándola de otros ecosistemas acuáticos costeros naturales no sometidos a fuertes presiones antrópicas, donde los ciclos se ajustan a las estaciones del año y a las características climáticas sin las interferencias que sufre la Albufera (Soria et al., 1987a; Vicente y Miracle, 1992).

\section{Características Hidrológicas de La Albufera y el Marjal}

La Albufera está situada al final de una cuenca de $917.1 \mathrm{~km}^{2}$, desde el nivel del mar hasta una altura de unos $1000 \mathrm{~m}$, limitando al Oeste con las Sierras de los Bosques, de la Cabresa y del Castellet. La cuenca vierte a la Albufera por diversos barrancos, de los que solo llegan a ella directamente dos por la zona Norte, el de Massanassa (también llamado de Torrent o de Poyo) y el de Beniparrell (o de Picassent), que son además los más importantes. Los demás barrancos vierten finalmente a acequias diversas entre huertas y arrozales. Entre ellos se podrían citar el del Hondo, el de la Berenguera y el del Agua que vierten a acequias de la zona Sur. De los citados, el principal es el de Massanassa, cuya cuenca es de $367.6 \mathrm{~km}^{2}$, que ya supone cerca del 
$40 \%$ de la cuenca total de la Albufera, y que es el que puede aportar, durante el periodo lluvioso del año, el mayor caudal superficial natural. La Albufera tiene además por una parte aportes de manantiales que surgen en su fondo (hoy en día muy venidos a menos), y por otra parte de otros barrancos y de los ullals en los alrededores del perímetro lacustre, cuyas aguas van a parar también a la red de acequias que terminan en el lago.

Finalmente, aparte de los aportes directos por precipitación (como promedio unos 500 mm año-'), la Albufera recibe también por la intrincada red de sesenta y tres acequias de riego, el agua procedente de los usos agrícolas, es decir el agua sobrante del riego de la Huerta Sur del río Turia y de la Ribera Baja del Júcar, a los que se suman los vertidos de aguas residuales de las poblaciones de su cuenca que llegan por las mismas acequias y barrancos.

Aunque la Albufera tiene una cuenca hidrográfica propia, la realidad es que ésta sólo proporciona una pequeña parte de las aportaciones, mientras que la gran mayoría de las aguas llegan desde el río Júcar, ya sea por la acequia Real o por las tomas de Sueca y Cullera. En este sentido, puede considerarse la Albufera como parte integrante del esquema hidrológico del río Júcar.

Los principales cauces que actualmente aportan aguas a la Albufera son:

- La carrera de "El Saler", con las aguas procedentes de la acequia del Oro, el trasvase de la EDAR de Pinedo y diversas acequias de la Vega que recogen los vertidos en todo o en parte de las poblaciones de Manises, Quart de Poblet, Alaquas, Aldaia, Xirivella, Mislata, Castellar, Oliveral, Pinedo, Alfafar. Sedaví y El Saler.

- El barranco de Chiva (también llamado de Poyo, Torrent o Massanassa) con aguas pluviales, residuales urbanas e industriales procedentes de una amplia cuenca en los términos de Chiva, Cheste, Quart de Poblet, Torrent, Picanya, Paiporta y Massanassa.

- Las acequias Nova de Silla, Oro de Silla, Senyoret y L'Alqueresía con aguas residuales fundamentalmente urbanas e indus- triales procedentes de Silla, El Romaní y Sollana, junto con sobrantes de riego.

- Las acequias de Campets y Overa, con aguas procedentes de sobrantes agrícolas de la Acequia Real del Júcar, y vertidos urbanos, desde Alginet, Benifaió, Almussafes y Sollana; más los vertidos industriales lejanos, pero no por ello menos peligrosos de los polígonos industriales de Alginet y Benifaió.

- La acequia Dreta, con aguas procedentes del Río Júcar, de algunos ullals y los sobrantes agrícolas de riego de las huertas y arrozales del término de Sueca.

La consecuencia es la aparición en el lago de una fuerte heterogeneidad espacial tal como se describe en los estudios realizados sobre la distribución del plancton y los pigmentos fotosintéticos (Alfonso y Miracle, 1990; López y Caselles, 1990; Soria et al. 1987b).

\section{MATERIAL Y MÉTODOS}

La medida de las aportaciones hídricas al ecosistema se ha realizado a partir de datos bibliográficos de trabajos existentes sobre apartados concretos (Alonso, 1974; Camarasa, 1995; COPUT, 1989; IGME-EPTTSA, 1986 y Rosselló, 1995) y a partir de medidas puntuales de caudal en diversas acequias y cauces naturales realizadas en 1988 .

La determinación de los caudales circulantes en las acequias se realizó por medio de aforos directos, empleando para ello un molinete universal de paso de hélice de $1 / 3$ de vuelta y diámetro de $12 \mathrm{~cm}$. En cada punto se medía la sección mojada y se determinaba la velocidad del agua en distintos puntos de la sección. En el caso de los ullals, el caudal de salida de la surgencia puede ser además una medida de la potencia del acuífero en ese punto. En algunos casos no era sido posible efectuar la medida por no permitirlo las condiciones de la surgencia del agua, o la situación del conjunto.

En otros casos, se empleó el método descrito por Escribá (1988), realizando en primer lugar el sondeo transversal en el punto de medida para 
calcular la sección del tramo. A continuación se introducían ondas coloreadas en la corriente de agua, para evaluar la velocidad máxima de la corriente. Posteriormente, se aplicaba un coeficiente de corrección según el material y revestimiento del tramo, según la fórmula de Fischer (Escribá, 1988) para cauces no torrenciales:

$$
\mathrm{V}_{\mathrm{m}}=\mathrm{K}{ }^{*} \mathrm{Vs}
$$

Siendo $\mathrm{V}_{\mathrm{m}}$ la velocidad media y $\mathrm{Vs}$ la velocidad medida, y teniendo $\mathrm{K}$ los valores según el tipo de cauce que se presentan a continuación:

$\begin{array}{ll}\text { Cauce con vegetación } & 0.55 \\ \text { Cauce con grava y piedras } & 0.64 \\ \text { Cauce con grava normal } & 0.71 \\ \text { Cauce de tierra } & 0.74 \\ \text { Cauce de mampostería } & 0.78 \\ \text { Cauce de hormigón o enlucido } & 0.80 \\ \text { Cauce revestido de metal } & 0.81\end{array}$

\section{RESULTADOS}

El Parc Natural de L'Albufera recibe aguas de cuatro orígenes principalmente: escorrentías superficiales naturales, aportes subterráneos, aguas residuales y sobrantes de riego. Evaluaremos el volumen de cada uno de ellos por separado.

\section{Escorrentías naturales}

Llegan principalmente por los barrancos que drenan la cuenca que termina en la propia laguna de la Albufera. De Norte a Sur son el barranco de Massanassa, el barranco de Beniparrell, el barranco Hondo, el barranco de la Berenguera y el barranco del Agua. Tan sólo el primero de ellos llega directamente a la Albufera encauzado entre motas, conservando su cauce como tal. Los otros cuatro terminan, en el momento entran en el territorio del Pare Natural, en canales de mayor o menor tamaño, que conducen sus aguas conjuntamente con otras residuales o sobrantes de riego. Señalaremos que la circulación natural sólo se produce durante los periodos de lluvia apreciable, que es capaz de producir escorrentía. Si las lluvias son lo suficientemente importantes se producen las típicas avenidas mediterráneas que fueron estudiadas en el barranco de Massanassa por Camarasa (1995) y sus efectos en la Albufera por Soria et al. (2001) en la gota fría de noviembre de 1988. El cálculo de la escorrentía total afluente a la Albufera fue realizado por primera vez por Alonso (1974), estimándola en $79,74 \mathrm{hm}^{3}$ año-'. De toda ella, la mitad (aproximadamente $40 \mathrm{hm}^{3}$ año-') son las propias escorrentías superficiales, y el resto aportaciones subterráneas que, como veremos en el apartado siguiente, en parte corresponden a las surgencias de aguas freáticas en los ullals, que a partir de estos puntos de surgencia circulan como aguas superficiales hasta su afluencia al lago.

La precipitación directa sobre el lago calculada a partir de la precipitación media ya es un volumen de $14 \mathrm{hm}^{3}$ año-'. Este volumen del conjunto de las escorrentías naturales discrepa notablemente del proporcionado por otros autores como la cita de Alonso por Roselló (1995), que magnifican dicha cifra hasta más de $300 \mathrm{hm}^{3}$ año-'.

\section{Aportaciones subterráneas}

Son de difícil evaluación. Sin embargo, se estimó en el "Plan Director de Saneamiento de la Albufera" el componente subterráneo de la escorrentía a través de la fórmula de permeabilidad de Darcy, conocida la superficie piezométrica, delimitadas las isopiezas de dos épocas del año, y determinada la transmisividad media. Este componente se ha evaluado por este procedimiento en 40 hm $^{3}$ año-' para el Parc Natural, lo que coincide con los datos de Alonso, 1974, si consideramos que este dato se refería al lago y su zona afluente. No se excluye que la explotación de pozos en el interior del Pare Natural, transfiera parte de la escorrentía subterránea a superficial, pero ello es poco relevante a nuestros efectos. Parte de esta escorrentía subterránea también aparece en los ullals, y como tal se ha evaluado en el estudio de estos sistemas acuáticos. 
Complementando lo expuesto, el estudio realizado por el Instituto Geológico y Minero de España en 1986, en colaboración con EPTISA (IGME, 1986) proporciona una media de 25 hm' año-' el agua subterránea aportada a la Albufera, con unos valores que oscilan según los años entre 19.6 y $28.4 \mathrm{hm}^{3}$ año-'. Como vemos, ambas cifras pueden ser coincidentes, puesto que la estimada en el "Plan Director" considera las aportaciones a todo el Parc Natural, mientras que la del IGME considera sólo los aportes al lago de la Albufera.

\section{Aguas residuales}

Llegan sin ningún tipo de depuración, o a lo sumo con algún tipo de pretratamiento, por medio de los propios cauces naturales y canales de riego, mezcladas con las aguas propias de estos. La separación del caudal residual del total conducido se ha realizado por dos procedimientos, y los resultados son suficientemente coherentes. El primero consiste en estimar la población servida, y asignarle una dotación directa o conocida de antemano. Casos singulares han sido los efluentes de aguas residuales de saneamiento de la fábrica Ford en Almusafes, que ha habido que estimar por separado, y los efluentes de la depuradora de Pinedo, que se transfieren parcialmente a la Albufera.

El segundo procedimiento consiste en calcular el contenido en fósforo de un agua residual tipo, y considerar que este elemento está prácticamente ausente en las restantes aguas (riego y escorrentía natural). Con estas premisas, poco alejadas de la realidad, se procede analizar el contenido en fósforo de las aguas afluentes al Parc Naturul de L'Albufera y se obtiene así el grado de dilución de presuntas aguas residuales en la corriente. De este modo puede determinarse el caudal de dichas aguas residuales para cada uno de los canales y acequias, y por lo tanto su volumen anual. Los resultados de estos dos métodos convergen en la cifra de $80 \mathrm{hm}^{3}$ año-'. Estos resultados también pensamos que son razonables si consideramos que la planta de tratamiento potabilizadora de Aguas de Valencia en Picassent toma en torno a los $52 \mathrm{hm}^{3}$ año-', y abastece a una parte de los municipios de la cuenca próxima al Parc Natural (además de parte de la ciudad de Valencia), mientras otros municipios y muchas industrias lo hacen por pozos propios.

\section{Aguas de riego}

Llegan a la Albufera por 63 cauces, en algunos de los cuales circulan aguas residuales y escorrentías naturales de barrancos que terminan en acequias. El mecanismo de distribución de estas aguas a través de la intrincada red de canales y acequias es complicado y variable, dependiendo de los ciclos de los cultivos y de inundación del marjal, conjugando los intereses de agricultores, pescadores y cazadores. Los cauces en unas ocasiones se bifurcan para suministrar las aguas; y en otros casos vuelven a reunir aguas de distintas procedencias. Las aguas sobrantes van siendo recogidas por azarbes que más adelante se convierten en nuevos canales de distribución aguas abajo, propiciando varias recirculaciones, hasta el drenaje final que tiene lugar en el mar o en la Albufera.

Estas aguas tienen su procedencia y entrada en el Parc desde tres orígenes:

A) Desde el río Turia, por una parte por la acequia del Oro, con los sobrantes de riego de las acequias de la margen derecha de la Vega de Valencia y desde allí se reparten por las acequias que confluyen hacia la Albufera. Por otra parte, los sobrantes de las acequias de Favara, Quart, Benager y Faitanar.

B) Desde la Acequia Real del Júcar, a partir de las tomas principales de las acequias de Algemesí, Sollana, Vella de Benifaió, El Romaní, Silla y Albal, y desde ellas hacia la Albufera a través de distintos brazales, acequias y azarbes que se van bifurcando.

C) Desde el río Júcar, por las tomas del azud de Sueca, que se bifurca en las acequias Nova, Mayor de Sueca y Muzquiz; y por la 
toma del azud de Cullera, por la acequia Madre de Cullera de la margen izquierda.

La Tabla 1 nos muestra los volúmenes en hm' año" tomados del río Júcar desde el año 1987 al 1996, medidos por el Organismo de Cuenca en Antella para la Acequia Real del Júcar, en Sueca para la acequia de la Margen Izquierda y en Cullera para la acequia Madre de Cullera de la Margen Izquierda, cuyos resultados suponen un aporte medio de aguas de 284 hm $^{3}$ año-' en la Acequia Real, de $165 \mathrm{hm}^{3}$ año-' en Sueca y sobre $49 \mathrm{hm}^{3}$ año-' en Cullera Margen Izquierda. Puesto que el caudal en origen de la Acequia Real del Júcar se deriva posteriormente en numerosas tomas, la parte proporcional de agua correspondiente a las tomas que riegan el Parc Natural supone un volumen medio de $65 \mathrm{hm}^{3}$ año-' de aportación.

Por lo tanto, el resultado del promedio de aportaciones de aguas de riego al Parc Natural de la Albufera es:

$\begin{array}{lr}\begin{array}{l}\text { Derivadas del Turia y otros } \\ \text { Derivadas de la }\end{array} & 45 \mathrm{hm}^{3} \text { año-' } \\ \begin{array}{l}\text { Acequia Real del Júcar } \\ \text { Derivadas del azud } \\ \text { de Sueca }\end{array} & 65 \mathrm{hm}^{3} \text { año-' } \\ \begin{array}{l}\text { Derivadas del azud } \\ \text { de Cullera }\end{array} & 165 \mathrm{hm}^{3} \text { año-' } \\ \text { TOTAL } & 49 \mathrm{hm}^{\prime} \text { año-' } \\ \end{array}$

En conjunto, las procedentes del río Júcar suman 279 hm $^{3}$ año-', frente a los 45 hm' año-' aportados por el Turia.

En este sentido, el aporte de aguas de riego especificado en el Plan Director para el Saneamiento de la Albufera (COPUT, 1989) dice que llegan al Parc Natural $321.86 \mathrm{hm}^{3}$ año-' procedentes del agua cedida desde el río Júcar más la Acequia Real del Júcar y $56.28 \mathrm{hm}^{3}$ año-' del agua cedida del Río Turia, en ambos casos, mezclada con aportes de vertidos urbanos, observándose pues una gran similitud entre ambas cifras.

La Tabla 2 nos muestra la distribución de las aportaciones anuales de cada acequia a partir de nuestras determinaciones puntuales, y la suma y porcentaje para cada una de las zonas en que hemos dividido el Parc Natural. Estos datos indican, que aunque haya 64 puntos de entrada, solo unos pocos son realmente importantes en lo referente al aporte de caudales. Concretamente Overa y Dreta (en la zona Sur) representan el $42.5 \%$ del caudal de entrada y van seguidas por las acequias que confluyen en Carrera de El Saler, Alqueresía, Fus y los barrancos de Beniparrell y Massanassa, contribuyendo todas ellas a un aporte que es prácticamente $75 \%$ del total. El volumen anual total de entradas fluyentes superficiales hacia la Albufera estimado por nuestros medios, con aforos directos, para el año 1988 ha resultado ser de $280.22 \mathrm{hm}^{3}$. Los puntos de medida coincidían

Tabla 1. Aportaciones totales anuales en $\mathrm{Hm}$ ' para cada una de las tomas de riego del río Júcar hacia el Parc Nuturul de L'Albufera y precipitación total recogida $(\mathrm{mm})$ correspondientes al año indicado. Annual total water supply (in hm ${ }^{3}$ ) from the river Jucar to euch irrigation channel leading to the Natural Park of L Albufera. Also indicated are annual rainfall levels (mm) collected during euch year

\begin{tabular}{|c|c|c|c|c|}
\hline A ño & Acequia Real en Antella & Toma de Sueca & Toma de Cullera & Pluviometría \\
\hline 1987 & 330 & 175 & 56 & 355 \\
\hline 1988 & 399 & 176 & 58 & 594 \\
\hline 1989 & 308 & 175 & 54 & 344 \\
\hline 1990 & 372 & 185 & 57 & 605 \\
\hline 1991 & 332 & 189 & 58 & 626 \\
\hline 1992 & 295 & 149 & 47 & 417 \\
\hline 1993 & 275 & 163 & 50 & 416 \\
\hline 1994 & 176 & 163 & 50 & 301 \\
\hline 1995 & 135 & 110 & 10 & 657 \\
\hline 1996 & 216 & 164 & 48 & 449 \\
\hline Media & 284 & 165 & 49 & 476 \\
\hline
\end{tabular}


Tabla 2. División de los aportes influentes a la Albufera según cinco sectores, indicándose los caudales aportados anualmente por cada acequia, así como la media diaria y el porcentaje que corresponde a cada sector zonal sobre el total aportado al lago. Inflows in each of five sectors of the Albufera, indicating annual dischurge. daily average discharge, and the contribution (in \%) of each sector in relation to the total water discharged to the lake.

ACEQUIA Volumen Hm' año-'

\section{ZONA NORTE}

Ac. de la Vinya

Ac. de L'Oliveral

Ac. de Pas Nou

0.62

Ac. del Oro

Ac. Nova de Alfafar

3.43

Ac. Nova de Alfafar

1.54

Ac. Rabisanxo

6.52

Ac. del Fus

3.00

Barranc de Massanasca

14.47

Ac. del Port de Catarroja

11.98

Ac. de Albal

8.73

Ac. de la Font de Mariano

9.94

Barranc de Beniparrell

9.15

Ac. Polig. Indust. Beniparrell

15.21

Ac. de Alapont

1.62

Ac. de Caminás

2.43

Aporte anual, hm'

\section{ZONA NOROESTE}

Ac. del Port de Silla

\section{ZONA OESTE}

Ac. Oro de Silla

Ac. del Ullal

4.34

Ac. de Les Pedres

2.21

Ac. de La Foia

3.82

Ac. El Calesero

\subsection{5}

0.20

Aporte anual, hm'

\section{ZONA SUROESTE}

Ac. El Senyoret $\quad 2.44$

Ac. El Ale $\quad 1.43$

Ac. del Desaigüe $\quad 4.71$

Ac. de L'Alqueresia $\quad 19.30$

Ac. de la Campana $\quad 3.58$

Ac. de Campets $\quad 6.70$

Ac. Nova $\quad 3.12$

Aporte anual, hm'

$\%$ sobre aporte anual

41.29

$14.70 \%$

\section{ZONA SUR}

Ac. de Overa

Ac. Dreta

85.84

Aporte anual, $\mathrm{hm}^{3}$

118.99

33.15

$\%$ sobre aporte anual

TOTAL. hm ${ }^{3}$ año ${ }^{-1}$

normalmente con los de toma de muestras, por lo que se consideran como entradas en el Parc Natural, en dirección hacia la Albufera. Este valor debe considerarse como muy bien aproximado, ya que los caudales de las principales acequias fueron medidos en varias ocasiones duran- 
te los primeros siete meses de ese año (de Enero a Julio), tanto durante periodos de lluvia, como de ausencia de ella y extrapolados de forma acorde con la climatología al resto del periodo anual. Además hay que destacar que la distribución de lluvias durante este año (1988) fue la habitual, recogiéndose $52 \mathrm{~mm}$ en invierno, 187 en primavera, 32 en verano y destacando los $323 \mathrm{~mm}$ en otoño, cuyo episodio de avenida se ha estudiado en Soria et al., 2001, pero que para nada afectó a nuestras medidas ya que el periodo inuestreado fue entre Enero y Julio.

Posteriormente, durante el año 1995, en las condiciones de extrema sequía, se realizaron

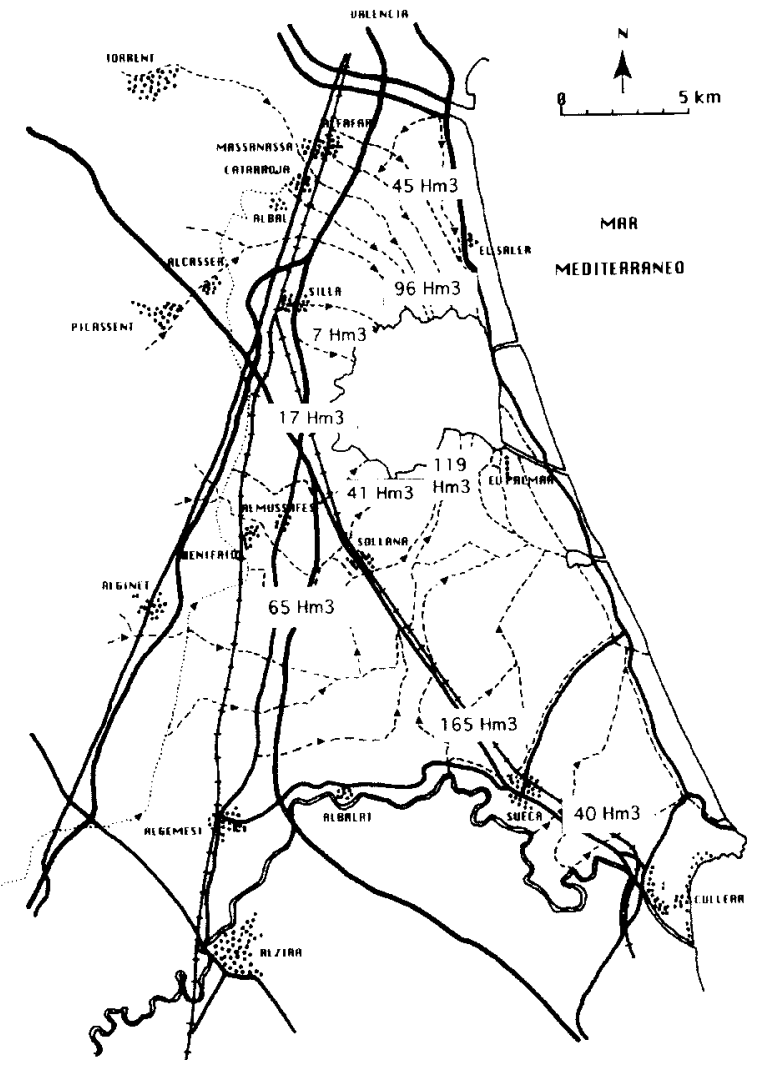

Figura 1. Promedio de las aportaciones anuales de aguas de riego que entran por las distintas zonas al Parc Natural, y aportaciones anuales que terminan en cada sector de la Albufera. Average of the annual irrigation water volumes inflowing into the different areas of the Natural Park and annual water discharge into each sector of the Albufera lagoon. mediciones de los aportes a la Albufera por los principales canales de entrada al lago, que fueron muy inferiores a las medidas de 1988 , un año normal. Al ser 1995 un año de extrema sequía, las aportaciones anuales fueron de $42 \mathrm{hm}^{3}$ año-', bastante alejadas de los $280 \mathrm{hm}^{3}$ año ${ }^{-1}$ evaluadas en 1988. Tengamos en consideración que los volúmenes suministrados al arrozal se redujeron un 40 $\%$ sobre lo habitual, y las aguas del lago en el periodo de cultivo eran bombeadas a las parcelas más próximas, produciendo una circulación inversa, lo que constituyó una situación anormal como también lo era la extrema sequía de este año.

\section{Evaporación}

Por otra parte debemos considerar también en nuestros cálculos las pérdidas que sufren los aportes al Parc Natural por la evaporación de las aguas mientras discurren por los arrozales y el propio lago. La componente de la evaporación está en función de la temperatura y de la superficie de agua libre que se presenta, que durante la época de cultivo es prácticamente toda la superficie del territorio más la propia evapotranspiración de las plantas del arrozal. El valor estimado para esta evaporación durante 1988 en el Plan de Saneamiento está en el orden de los $15 \mathrm{hm}^{3}$ año-' para la Albufera, y de unos $75 \mathrm{hm}^{3}$ año-' para todo el Pare Natural, en gran parte concentrado durante los periodos de inundación.

\section{Resumen de aportaciones}

La suma final de aportaciones totales al Pare Natural serían las aportaciones naturales superficiales y subterráneas, las aguas residuales y las aguas de riego menos la evapotranspiración en el marjal y el propio lago, o sea un volumen aproximado de 400 hm' año-'.

Agua de escorrentía superficial

Agua de escorrentía subterránea

$40 \mathrm{hm}^{3}$ año-' $\quad 8 \%$
$40 \mathrm{hm}^{3}$ año-' $\quad 8 \%$


Agua residual

Aguas de riego

TOTAL

Pérdidas por

evapotranspiración

Total neto

$-75 \mathrm{hm}^{3}$ año-'

409 hm $^{3}$ año-'

Con todos estos datos de partida, se tendría la siguiente situación de aportaciones en un año normal, expresiva de las entradas de agua en el lago de la Albufera.

Agua de escorrentía

superficial

Agua de escorrentía

subterránea

Agua residual

Sobrantes de riego

TOTAL

$40 \mathrm{hm}^{3}$ año-' $14 \%$

$40 \mathrm{hm}^{3}$ año-' $14 \%$

80 hm' año-' $29 \%$

$120 \mathrm{hm}^{3}$ año-' $43 \%$

280 hm $^{3}$ año-' $100 \%$

Pérdidas por

evaporación en el lago $\quad-15$ hm' año-'

Total neto

$26.5 \mathrm{hm}^{3}$ año-'

Por lo tanto, vistos los resultados expuestos, concluimos que las aportaciones medias totales al Parc Natural deben oscilar en un volumen que se acerca a los $500 \mathrm{hm}^{3}$ año-', pero sólo un

Tabla 3. Cubicación fraccionada de la Albufera en cinco sectores practicados de forma acorde con la circulación del agua en el lago, indicando además los caudales aportados a cada sector y los tiempos de renovación estimados. Volume of each of five sectors of the Albufera. Sectors were divided according to the pattern of water circulation in the lake. Flows contrihuted by each sector und the estimated renewal times are also indicated.

\begin{tabular}{lcccc}
\hline ZONA & $\begin{array}{c}\text { Volumen } \\
\mathrm{hm}^{3}\end{array}$ & $\begin{array}{c}\text { Aporte neto } \\
\mathrm{m}^{3} \mathrm{dia}^{-1}\end{array}$ & \multicolumn{2}{c}{ Tiempo renovación } \\
Días & Veces/año \\
\hline Albufera & 27.10 & 726359 & 37 & 9.8 \\
Norte & 4.60 & 255743 & 18 & 20.3 \\
Noroeste & 5.56 & 10051 & 554 & 0.7 \\
Oeste & 7.98 & 35131 & 227 & 1.6 \\
Suroeste & 5.56 & 104641 & 53 & 6.9 \\
Sur & 3.39 & 320795 & 11 & 34.6 \\
\hline
\end{tabular}

poco más de la mitad llega realmente hasta la Albufera. Del volumen total del agua aportada al Parc Natural, dos terceras partes son aguas de riego; y de ellas, el $86 \%$ proceden directamente desde el río Júcar por las acequias de Sueca y Cullera o por las tomas de la Acequia Real del Júcar, con un volumen anual medio en este decenio (Tabla 1) de 279 hm $^{3}$ año-'. De nuevo la discrepancia con los datos citados por Roselló (1995) es notable, pues se daban cifras para el agua de riego de unos $33 \mathrm{hm}^{3}$ año-'.

La figura 1 nos muestra sobre el esquema del Parc Natural, el resumen de las aportaciones por cada toma y las entradas por cada canal hacia la Albufera.

\section{DISCUSIÓN}

El año 1988 tuvo una distribución de lluvias que podemos considerar la normal de esta década (Tabla 1), con un máximo otoñal importante, si bien durante la época de nuestras mediciones de caudal no hubo lluvias importantes.

En la Tabla 3 se especifican, junto a los volúmenes asignados para cada una de las cinco zonas en las que dividimos la Albufera (Fig 2), los diferentes caudales que llegan a cada una de éstas, así como una estima de los tiempos de renovación correspondientes suponiendo una situación en la que los aportes fueran continuados y estables, sin aportaciones extraordinarias y deducida la evaporación. Se observan grandes diferencias entre los distintos sectores de manera que una gran parte de la Albufera (zonas NO y O) se renueva muy lentamente, solo 1 ó 2 veces por año, mientras que los sectores cercanos a las gola del Pujol y La Sequiota (N y $\mathbf{S}$ respectivamente) son los únicos cuya renovación es aproximadamente quincenal. La zona SO quedaría en una situación intermedia con unas 7 renovaciones por año. Adicionalmente, si consideramos la discontinuidad de los aportes hídricos al lago, la renovación real de las aguas será más importante en los periodos de mayor circulación de aguas y menor en los que los aportes son muy bajos o inexistentes. 
Debido a su gran superficie y escasa profundidad, se detecta una heterogeneidad espacial de la Albufera, consecuencia de que la renovación y flujos de agua son diferentes en sus distintas zonas, lo que se pone de manifiesto en todos los estudios realizados sobre el plancton o la química del agua de la Albufera por distintos autores (Alfonso y Miracle, 1990; López y Caselles, 1990; Soria et al. 1987b), y ello es lo que nos ha inducido a sectorizar el lago en cinco subzonas, en base a las pautas de circulación del agua observadas y a su afectación por caudales de muy distinto origen, cuantía, tipo de mineralización y calidad de sus aguas.

Con respecto a los valores de las aportaciones hídricas a la Albufera, no es posible considerar como válidos los proporcionados por Roselló (1995) por cuanto son ínfimos respecto a los suministros en origen a las diferentes zonas regables, a diferencia de los volúmenes considerados

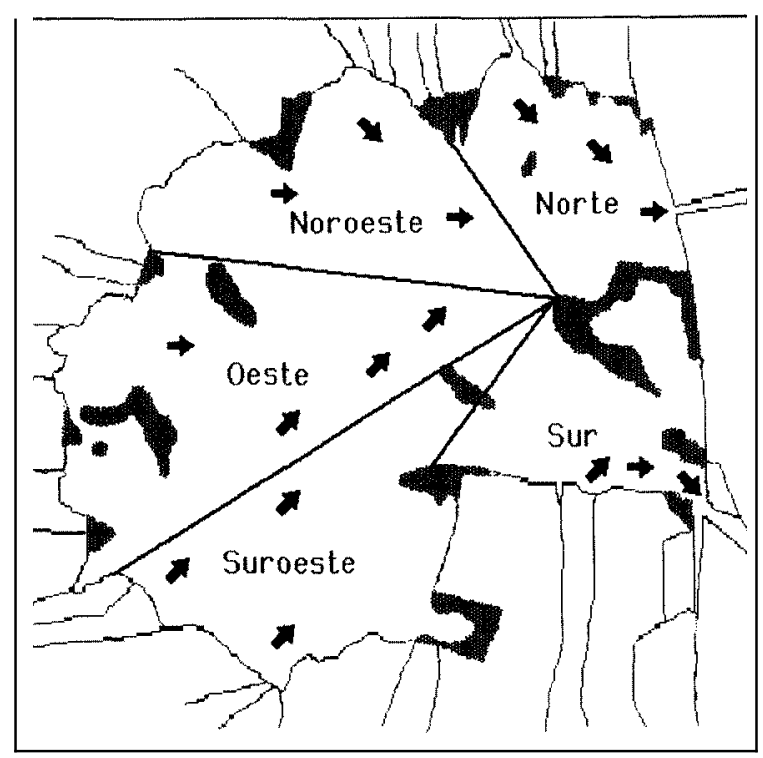

Figura 2. Esquema de la Albufera indicando su distribución zonal y los flujos de las corrientes de agua en cada una de las zonas con dirección hacia las dos salidas (Gola del Pujol y la Sequiota, que comunica a su vez con las Golas del Perellonet y del Perelló). Outline of the Albufera indicating the zonal distribution und directions of water circulution in each of the lake areas. Water flows towards two outlets called "Gola del Pujol" and "la Sequiota", which in turn flows toward the "Golas del Perellonet" and the "Perelló". en nuestro estudio, que son coherentes con los suministrados para el regadío. También parece criticable a la luz de estos resultados el volumen de $100 \mathrm{hm}^{3}$ año-' que ha reservado para la Albufera el Plan Hidrológico. Pese a ello, hay que hacer la salvedad que las reservas del Plan Hidrológico se refieren a los volúmenes de aguas superficiales suministrados en origen, tanto desde la Acequia Real como desde Sueca, aunque el propio Plan no aclara si este volumen es exclusivo para el lago y adicional a las aguas de riego necesarias o no. En todo caso, a este volumen deben añadirse los correspondientes a las escorrentías naturales más las trasferencias de aguas residuales depuradas. La cifra obtenida acumulando estas cantidades alcanzaría un volumen de $260 \mathrm{hm}^{3}$ anuales. La gestión adecuada de este volumen, haciéndolo circular en dirección a la Albufera y complementado con una gestión razonable de los desagües al mar, generalmente regulados por compuertas ubicadas en el tramo final de los canales, además de las que regulan el flujo en las Golas de la Albufera, debería ser suficiente para garantizar una calidad razonable del ecosistema. Favorecer los flujos maniobrando las compuertas para que los caudales salgan al mar por la Gola del Pujol es el primer factor. El segundo sería suministrar los volúmenes reservados para la Albufera por el Canal Júcar-Turia y enviarlos por los barrancos del Agua, Hondo, Beniparrell y Massanassa durante los periodos de menor flujo en el lago. Con ello se contribuiría a mejorar la calidad del lago y a mantener los ecosistemas fluviales de estos cauces naturales.

\section{CONCLUSIONES}

Es precisamente por los graves problemas de contaminación que sufre la Albufera y cuya solución pasa en parte por la desviación de caudales contaminados fuera del lago (obras que están en fase de realización), que hemos de insistir en la necesidad de no restar agua de buena calidad al sistema, considerando como tal no solo el lago de la Albufera sino también el marjal. Al lago deben llegar los 260 hm³ año-' mínimos procedentes de las zonas 
de riego reguladas y otras aportaciones superficiales o subterráneas, reemplazando el $30 \%$ de agua residual que actualmente llega al lago por aportes no contaminados. Se deben asegurar los $100 \mathrm{hm}$ ' año-' que consigna el Plan Hidrológico de la Cuenca del Júcar independientemente de la cuantía de los sobrantes de riego, que a consecuencia de una mejor gestión del regadío tenderán a reducirse progresivamente. La mejor gestión del agua debe encaminarse a mantener los aportes hídricos al lago y a las reservas naturales del Parc Natural de l'Albufera especialmente en los periodos de necesidad, de modo que se saque el mejor partido de los recursos presentes. En este marco queremos insistir en la posibilidad de hacer llegar agua del Júcar lo mas al Norte posible, utilizando el Canal Júcar - Turia y los barrancos afluentes a la Albufera, así como una adecuada gestión de las compuertas que controlan el desagüe al mar del marjal, y muy especialmente las existentes en el tramo terminal de los canales de la zona Sur del Parc, consiguiendo con todo ello hacer llegar al lago la mayor parte de las aguas superficiales sobrantes del riego en la zona de Sueca.

\section{BIBLIOGRAFIA}

ALFONSO, M. T. Y M. R. MIRACLE. 1990. Distribución espacial de las comunidades zooplanctónicas de la Albufera de Valencia. Scientia gerundensis 16(2): 11-25.

ALONSO, J. J. 1974. Balance hídrico y estudio de los aportes sólidos a la Albufera. Inst. Hidrología y Medio Natural. Publ. Univ. Politécnica de Valencia.

CAMARASA, A. M. 1995. Génesis de crecidas en pequeñas cuencas semiáridas: Barranc de Carraixet y Rambla de Poyo. MOPTMA. Madrid. 252 p.

CASELLES, V., M. J. LÓPEZ, y J. M. SORIA. 1986. Estudio del estado trófico del lago de la Albufera (Valencia) a partir de imágenes del Landsat-5 (TM). I Reunión Científica del Grupo de Trabajo en Teledetección. Barcelona: 33-36.

COPUT. 1989. Plan director para el saneamiento integral del lago de la Albufera. Generalitat Valenciana. Clave 10/87-OP.OH.

ESCRIBÁ BONAFÉ, D. 1988. Hidráulica para Ingenieros. Lib. Editorial Bellisco. Madrid.

I.G.M.E. - EPTISA. 1986. Evaluación a nivel de aplicación de los recursos hídricos subterráneos disponibles en los acuiferos del sector sur del sistema 51 (Plana de Valencia).Posibilidades de su utilización inmediata. MOPU. Madrid.

LÓPEZ GARCÍA, M. J. \& V. CASELLES. 1990. A multi-temporal study of chlorophyll a concentration in the Albufera lagoon of Valencia, using thematic mapper data. Int. J. Remote Sensing, 11: 301-311.

ROSSELLÓ, V. M. 1995. L'Albufera de Valencia. Publicacions de l'Abadia de Montserrat. 190 pp.

SÁNCHEZ DÍAZ, J. 1991. Plan Especial de protección del Parque Natural de la Albufera. Generalitat Valenciana. Conselleria de Medi Ambient. Valencia. $148 \mathrm{pp}$.

SORIA, J. M., M. R. MIRACLE y E. VICENTE. 1987a. Aporte de nutrientes y eutrofización de la Albufera de Valencia. Limnetica, 3: 227-242.

SORIA, J. M., M. R. MIRACLE y E. VICENTE. 1987b. La Albufera de Valencia: comunidades fitoplanctónicas en la campaña 1992-93. Act. VI Simp. Nac. Bot. Cript., 165-172.

SORIA, J. M., E. VICENTE \& M. R. MIRACLE. 2001. The influence of flash floods in the limnology of the Albufera of Valencia lagoon (Spain). Verh. Internat. Verein. Limnol., 27: 2232-2235.

VICENTE, E \& M. R. MIRACLE. 1992. The coastal lagoon Albufera de Valencia: An ecosystem under stress. Limnetica, 8: 87-100. 